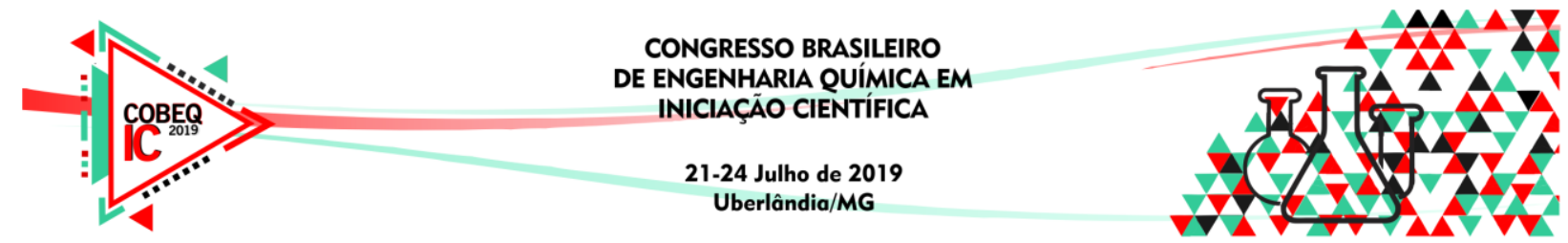

\title{
SINTESE DE CATALISADORES DE DIÓXIDO DE TITÂNIO DOPADOS COM METAL PARA APLICAÇÃO EM TRATAMENTO DE RESÍDUOS.
}

\author{
J. E. SAVOIA ${ }^{1}$, J.S.P. SANTOS ${ }^{1}$, V.A.S. RIBEIRO ${ }^{2}$, A. M. F. LIMA $^{1}$ e R. G. MARQUES ${ }^{1}$ \\ ${ }^{1}$ Universidade Tecnológica Federal do Paraná - Campus Apucarana, Engenharia Química; \\ ${ }^{2}$ Universidade Tecnológica Federal do Paraná - Campus Apucarana, Engenharia Têxtil; \\ E-mail para contato: jaquelinesavoia@alunos.utfpr.edu.br
}

\begin{abstract}
RESUMO - A fotocatálise heterogênea vem sendo estudada para o tratamento de efluentes contendo compostos recalcitrantes. A síntese de fotocatalisadores nano particulados vem sendo desenvolvida ao passar dos anos, com intuito de melhorar o processo de fotocatálise heterogênea. $O$ presente trabalho propõe avaliar a atividade fotocatalítica de catalisadores sintetizados com oxido de titânio dopado com Cério, Bismuto e Lântanio, através de impregnação úmida na degradação do corante azul de metileno. Os catalisadores foram sintetizados contendo $0,5 \%$ do dopante em massa.Verificou-se que o fotocatalisador mais ativo foi o $\mathrm{Bi} / \mathrm{TiO}_{2}$, seguido do $\mathrm{Ce} / \mathrm{TiO}_{2}$ e do $\mathrm{La} / \mathrm{TiO}_{2}$.
\end{abstract}

\section{INTRODUÇÃO}

Os processos biológicos, sistemas convencionais de tratamento de esgoto e água, possibilitam com baixo custo operacional a remoção da demanda química de oxigênio (DQO) dos sólidos suspensos totais (SST) e nutrientes que compõem o esgoto sanitário; porém apresentam baixa eficiência de remoção de fármacos e outros compostos sintéticos, o que faz com que o estudo de novas alternativas de tratamento seja indispensável. (Sant'Anna,2010).

Os Processos Oxidativos Avançados (POAs) têm se mostrado uma alternativa para o tratamento destes efluentes os quais são definidos por Herrmann (1999) como processos com potencial de produzir radicais hidroxila $\cdot \mathrm{OH}$, espécies altamente oxidantes, reagirem com a matéria e tem como produto final dióxido de carbono, água e íons inorgânicos. Os processos de oxidação avançada (POA) são usados para oxidar os componentes orgânicos complexos encontrados em águas residuais, que não são facilmente biodegradados em produtos finais mais simples (METCALF, 2003).

Entre os POAs, destaca-se a fotocatálise heterogênea, processo que envolve irradiação de um óxido semicondutor. São utilizados óxidos de metais semicondutores, entre os quais, o dióxido de titânio $\left(\mathrm{TiO}_{2}\right)$ é o catalisador mais utilizado na fotocatálise heterogênea sendo de baixo custo, insolúvel em água, não tóxico, além de estável em uma ampla faixa de pH (NOGUEIRA; JARDIM, 1998). O início do processo ocorre com a irradiação do semicondutor a qual a energia de radiação tem que ser igual ou superior à sua energia de 


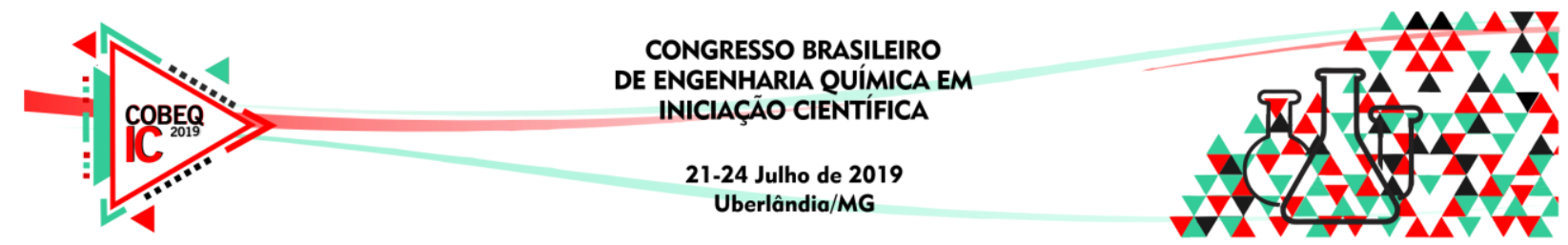

"band gap", para que ocorra a absorção de fótons e a geração de pares elétron-lacuna, os quais se dissociam em elétrons livres na banda de condução e lacunas na banda de valência com potencial para gerar radicais $\bullet \mathrm{OH}$ a partir de moléculas de água ou efluente adsorvido (HERRMANN, 1999). Os radicais hidroxila são altamente oxidantes, e reagem com compostos orgânicos, podendo levar a mineralização completa dos mesmos.

O dióxido de titânio apresenta vantagens para a fotocatálise, porém outras alternativas mais eficazes e de baixo custo têm sido buscadas para modificadores, como por exemplo os dopantes que podem contribuir positivamente nas propriedades do $\mathrm{TiO}_{2}$, como na fase cristalina, morfologia, e consequentemente melhorar os resultados de degradação de compostos orgânicos por fotocatálise. (SANTOS et al., 2011).

Para a síntese de catalisadores tem-se comprovado a influência das ondas sonoras sobre sistemas químicos, determinada efeito sonoquímico que de acordo com Gedaken (2004) e tem se provado uma técnica de efeitos uteis para a geração de compostos com propriedades incomuns, a alta energia permite que muitas ligações químicas ocorram.

Para caracterização dos catalisadores o ponto de carga zero é um indicador de qual valor de $\mathrm{pH}$ o sólido tem carga superficial nula $\left(\mathrm{pH}_{\mathrm{pcz})}\right.$, onde o número de cargas positivas e negativas é igual. De acordo com SILVA et al (2010), este parâmetro é importante para avaliar o porquê a ocorrência da adsorção tem dependência do pH da solução.

Nesse contexto, o presente trabalho tem por objetivo sintetizar catalisadores com dióxido de titânio dopado com Bismuto, Lantânio e Cério com fins acadêmicos para pesquisa na área de processos oxidativos avançados.

\section{METODOLOGIA}

\subsection{Síntese dos catalisadores}

Foram sintetizados os seguintes catalisadores: $\mathrm{Bi} / \mathrm{TiO}_{2}(0,5 \%), \mathrm{La} / \mathrm{TiO}_{2}(0,5 \%)$, $\mathrm{Ce} / \mathrm{TiO}_{2}(0,5 \%)$. Todos os catalisadores foram sintetizados através da metodologia liquidoliquido pela adição da solução salina, os quais foram utilizados sais de nitrato de cério iv, acetato de lantânio e salicilato de bismuto, e solução de dióxido de titânio puro, na proporção indicada para síntese de 100 gramas de cada um dos catalisadores. Utilizou-se de ultrassonografia durante 10 minutos. Posterior as amostras foram colocadas em estufa durante 24 horas para garantir a secagem em seguida calcinadas na mufla a $450^{\circ} \mathrm{C}$ por 4 horas.

\subsection{Caracterização dos catalisadores}

Para analisar a eficiência dos catalisadores foram realizados testes fotocatalíticos, Os testes foram realizados em triplicata, utilizando béqueres de $100 \mathrm{~mL}$, utilizando um reator do tipo batelada feitos com chapas de alumínio, de dimensões $60 \mathrm{~cm}$ x $71 \mathrm{~cm}$ x $61 \mathrm{~cm}$ (Altura x 


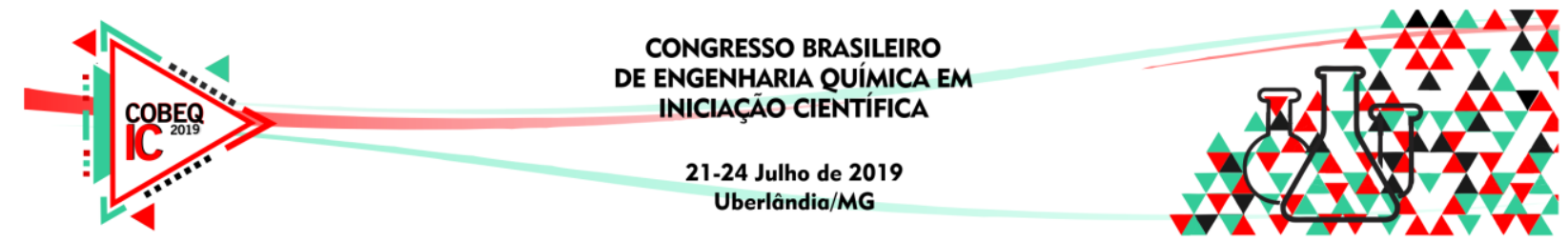

Largura x Comprimento), com 15 de pontos de agitação magnéticas, representados na figura 1.

Figura 1. Representação do agitador magnético com 15 pontos de agitação.

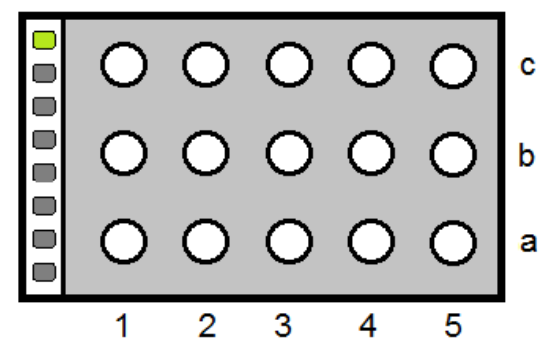

O efluente utilizado foi uma solução de azul de metileno na proporção $0,01 \mathrm{~g} / \mathrm{L}$ e a concentração de catalisador foi de $1 \mathrm{~g} / \mathrm{L}$ que foi colocado imerso na solução sob agitação constante e exposto a luz ultravioleta, o processo repetiu-se para cada um dos catalisadores, como registrado na figura 2. Como fonte de radiação foram utilizadas 4 lâmpadas de vapor de mercúrio $15 \mathrm{~W}$ cada. Foi realizado teste de adsorção para verificar a degradação da solução sem a radiação. Em todos os testes foram coletadas amostras nos tempos de 10, 20, 30, 40, 50 e 60 minutos. As amostras foram centrifugadas por 15 minutos a $3000 \mathrm{rpm}$, e em seguida analisadas por espectrofotometria UV-VIS no comprimento de onda de maior absorção.

Figura 2. Fotografia do reator utilizado no estudo.

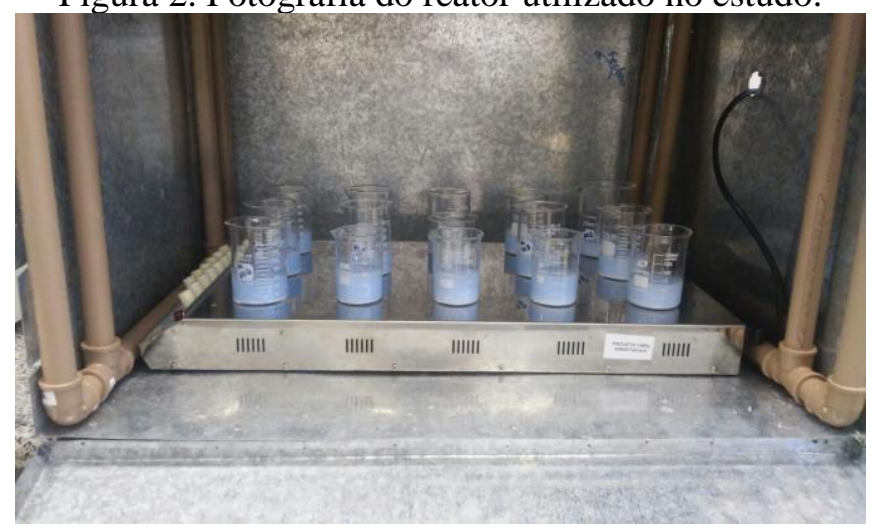

Para determinar o ponto de carga nula dos catalisadores sintetizados foi utilizado a análise gráfica do $\mathrm{pH}_{\mathrm{pcz}}$, que consiste em utilizar uma solução de $\mathrm{NaCl}$ na proporção $20 \mathrm{~mL}$ $(0,1 \mathrm{~mol} / \mathrm{L})$ de solução para $20 \mathrm{mg}$ de catalisador. Calibrou-se o $\mathrm{pH}$ inicial de cada solução (2, $4,6,8,10,12)$ ajustando com $\mathrm{HCl}$ ou $\mathrm{NaOH}(0,1 \mathrm{~mol} / \mathrm{L})$ os testes foram feitos em triplicata e ficaram em agitação constante por $24 \mathrm{hrs}$, então foi aferido o $\mathrm{pH}$ final de cada uma das soluções e pode se assim determinar os pontos de carga nula, por método gráfico com o auxílio do Excel.

\section{RESULTADOS E DISCUSSÕES}




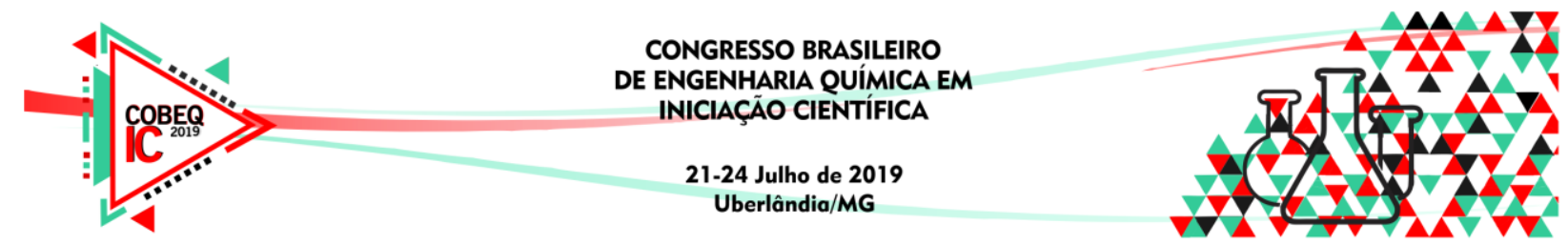

Para avaliação da degradação do azul de metileno na solução foi feita a varredura da solução de 100ppm do corante azul de metileno, foi realizado uma varredura para determinar o comprimento de onda de maior absorbância, nesta verificou-se que o pico máximo foi de $654 \mathrm{~nm}$, então todas as leituras foram feitas neste comprimento de onda.

Os resultados dos testes fotocatalíticos estão apresentados na Figura 3, foi determinado a média entre a triplicata de cada um dos catalisadores no tempo indicado, a partir da absorbância foi possível determinar a porcentagem de remoção do corante azul de metileno com o tempo.

Figura 3 - Gráfico de comparação C/Co x tempo

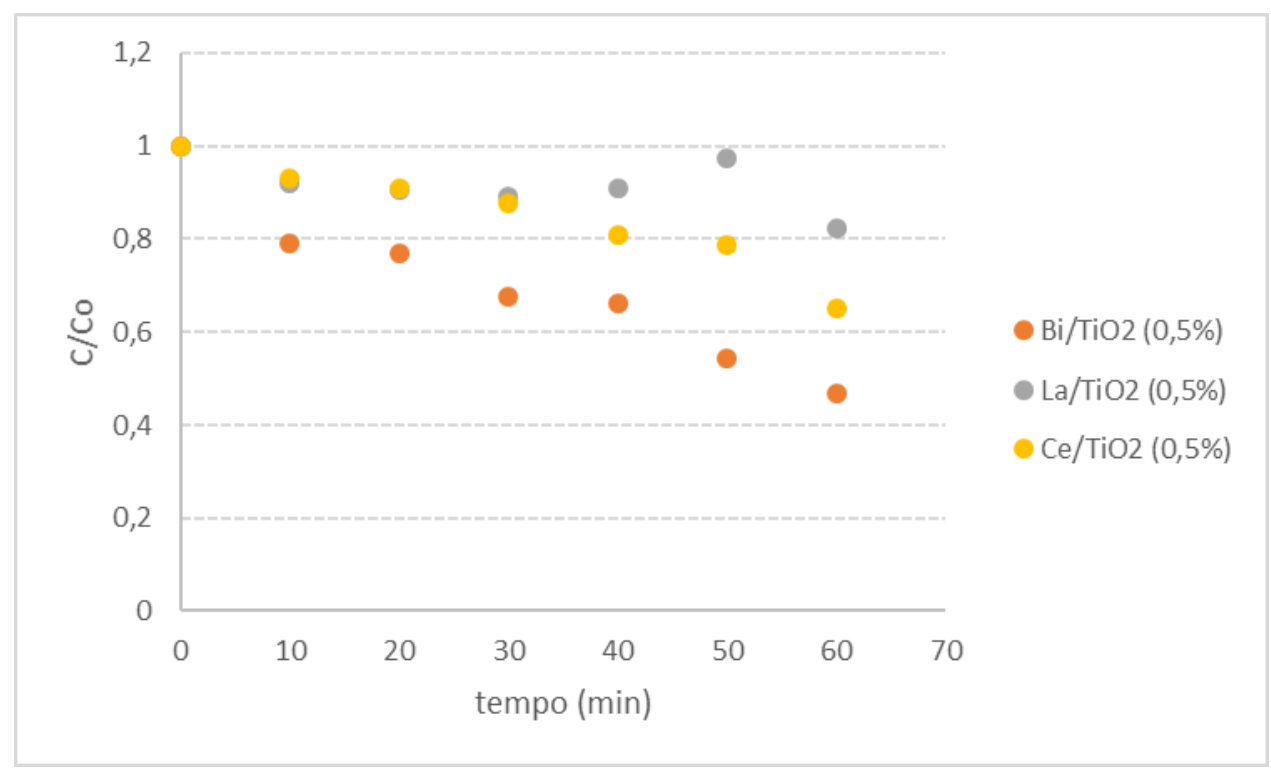

A partir da Figura 3 verifica-se que ocorreu a degradação do azul de metileno em todos os catalisadores. Observou-se que para o catalisador dopado com lantânio o ponto em 50 minutos se aproximou de 1 o que pode ser atribuído a um possível erro na leitura do equipamento.

Dadas as condições do reator e do tempo foi possível determinar a maior remoção em 47\%, já sendo possível notar diferenças na coloração, como registrado na figura 4, onde o 1 é a remoção final de $\mathrm{Bi} / \mathrm{TiO}_{2}$ em 60 minutos de reação, 2 é a remoção de $\mathrm{La} / \mathrm{TiO}_{2}$; e 3 é a remoção de $\mathrm{Ce} / \mathrm{TiO}_{2}$.

Figura 4 - Resultado da degradação do azul de metileno por fotocatalise para 60 minutos de reação.

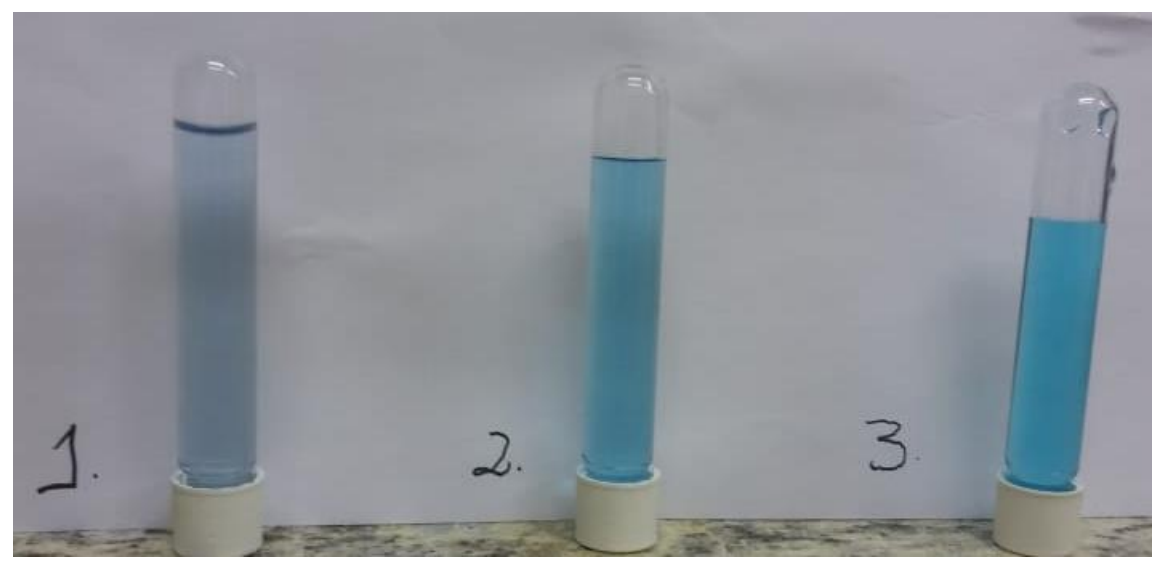




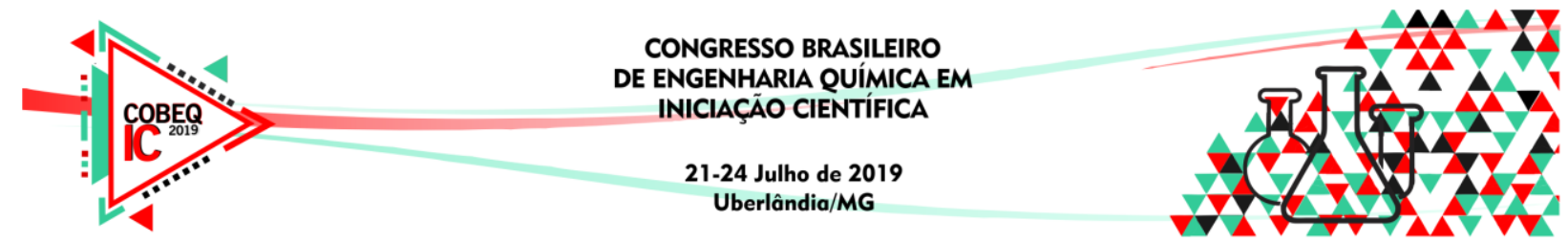

É possível observar a maior degradação para o oxido de Titânio dopado com Bismuto confirmando os dados obtidos através da espectrometria o que pode ser atribuído ao $\mathrm{pH}$ operante do catalisador. Para a determinação do ponto de carga nula foi utilizado método gráfico como exemplificado na figura 5

Figura 5 - determinação do ponto de carga nula.

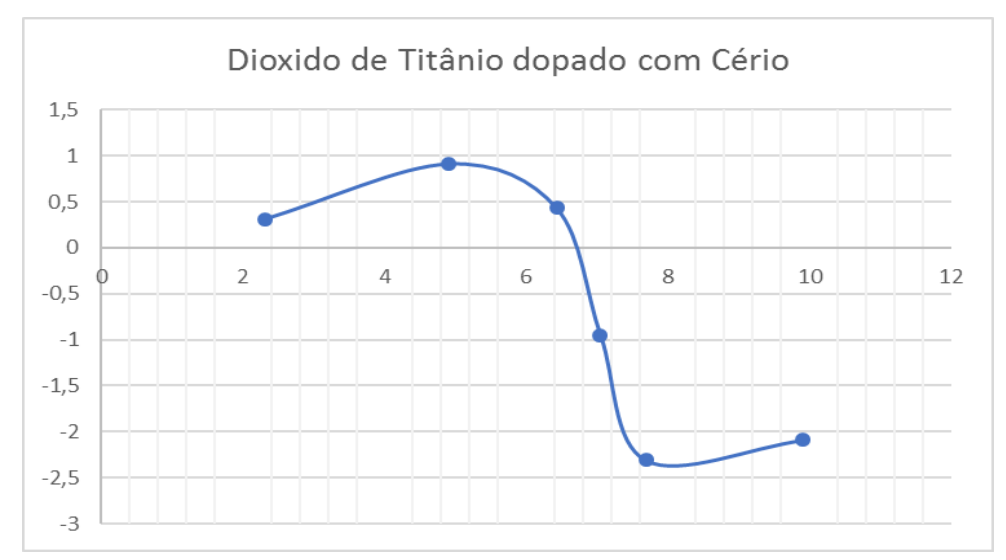

Para cada catalisador foi utilizado o mesmo método e encontrado o ponto de carga nula como apresentado:

- Dioxido de Titânio dopado com Bismuto: 8,4.

- Dioxido de Titânio dopado com Lântanio: 6,2.

- Dioxido de Titânio dopado com Cério: 6,4.

Observou-se que o catalisador $\mathrm{Bi} / \mathrm{TiO}_{2}(0,5 \%)$ opera em $\mathrm{pH}$ básico foi o que obteve maior porcentagem de remoção do azul de metileno, seguido do catalisador $\mathrm{Ce} / \mathrm{TiO}_{2}(0,5 \%)$ e do catalisador de $\mathrm{La} / \mathrm{TiO}_{2}(0,5 \%)$ que tem ponto de carga nula próximos.

\section{CONCLUSÃO}

Os resultados obtidos foram positivos para fotocatálise heterogênea, sendo o catalisador de dióxido de titânio dopado com bismuto o de maior degradação para as condições do reator e tempo de reação. Este trabalho teve caráter significativo para a pesquisa de síntese de catalisadores em processos oxidativos avançados aplicada em tratamento de resíduos, permitindo novas pesquisas para aprimorar o uso e as condições das reações. 


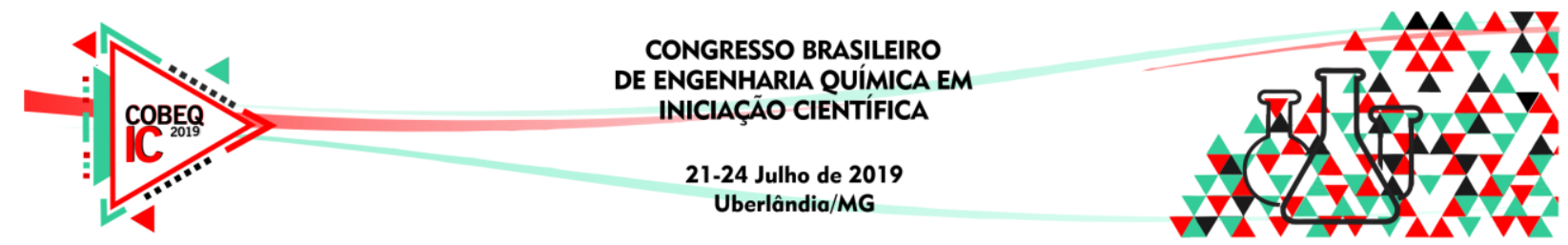

\section{REFERÊNCIAS}

GEDANKEN, A. Ultrasonics Sonochemistry, v. 11, p. 38, 2004.

HERRMANN, J.M. Heterogeneous photocatalysis: fundamentals and applications to the of various types of aqueous pollutants. Catalysis Today, v. 53, pp. 115-129, 1999.

METCALF E. Wastewater Engineering - Treatment and Reuse.4º ed, 2003.

NOGUEIRA, R. F. P.; JARDIM, W. F.; A Fotocatálise Heterogênea e sua Aplicação Ambiental. Química Nova. v. 21, n. 1, pp. 69-72. 1998.

SANT'ANNA G.L.J. Tratamento biológico de efluentes aplicações, Rio de Janeiro; interciência 2010, 418p.

SANTOS, Silvanice A. L. et al. Síntese e Caracterização de Pós de $\mathrm{TiO}_{2}$ Modificados com Silício e Zircônio Preparados Pelo Método Sol-Gel. Naviraí, 2011.

SILVA, F. M.; SANTANA, S. A. A.; BEZERRA, C. W. B; SILVA, H. A. S.; Adsorção do Corante Têxtil Azul de Remazol R por Pseudocaule da Bananeira. São Luís, v. 17 n. 3 , p. 71-77, 2010; 